Short title: CHILDHOOD ABUSE AMONG HOMELESS PEOPLE

Prevalence of childhood abuse among people who are homeless in Western countries: A systematic review and meta-analysis

Eva C. Sundin ${ }^{1 *}$, Thom Baguley ${ }^{1}$

${ }^{1}$ Division of Psychology, Nottingham Trent University, Nottingham NG1 4BU, UK

* Requests for reprints should be addressed to Eva Sundin, Division of Psychology, Nottingham Trent University, Nottingham NG1 4BU, UK (e-mail: eva.sundin@ntu.ac.uk). 
Keywords: childhood physical abuse; childhood sexual abuse; adult people who are homeless; meta regression analysis 


\title{
Prevalence of childhood abuse among people who are homeless in Western countries: A systematic review and meta-analysis.
}

\author{
INTRODUCTION \\ Over the last forty years, it has been increasingly recognised that homelessness is a \\ multifaceted problem. Unfavourable structural conditions, for example a shortage of \\ affordable housing and unemployment, have been identified as prerequisites that explain \\ widespread homelessness (broadly defined to include rough sleeping, living in emergency or \\ insecure accommodation) [1-3]. Furthermore, because the ability to access employment is \\ limited by the lack of a stable address, homelessness is associated with poverty [4,5]. Third, \\ people who are homeless often experience severe difficulties with housing related services, \\ health services and education $[6,7]$. For many, these problems are sustained or exacerbated by \\ poor physical and mental health and the need to support alcohol or drug dependencies $[2,8]$. \\ In fact, a recent review article investigated the mortality rate among the homeless in Boston \\ and found that the all-cause mortality rate remains high and unchanged since 1988 to 1993
} [9].

Despite the expansion of research on issues that cause and surround homelessness, the number of people experiencing homelessness in most, if not all, Western countries has increased or remained stable during the past decade [10-12]. There is also an increase in the number of people with mental illnesses living on the streets or in shelters or hostels $[13,14]$ and a nationwide, prospective, register-based cohort study of homeless people in Denmark showed that registered substance abuse disorder was associated with the highest mortality risk compared with no psychiatric contact registered [15]. Several review articles have confirmed that psychiatric disorders are more prevalent among people who are homeless in 
Western countries than in the age-matched general population and they are more likely to have alcohol and drug dependence [16-20].

The role of traumatic experiences in the homeless is a pertinent issue that has been studied by many researchers. Some authors have used Seligman's theory of learned helplessness [21] to explain how, for many, becoming homeless is a traumatic event in itself (22-24]. This is because, "like other traumas, becoming homeless frequently renders people unable to control their daily lives" [23, p 122] In addition and parallel with the body of research demonstrating that experiences of childhood abuse in members of the general population is linked to, e.g., mental health problems and drug and alcohol abuse later in life [25-26], many researchers have investigated the role of child maltreatment in adult people who are homeless. Four types of child maltreatment are generally recognised: physical abuse; sexual abuse; emotional abuse; and neglect. However, the impact of childhood physical abuse on health and wellbeing later in life has been studied less than childhood sexual abuse, and childhood emotional abuse and neglect has received the least scientific attention [26-30].

Several reasons for this "neglect of neglect" [31, p 530] has been discussed in the literature, most importantly a lack of consistency and clarity regarding definitions of neglect $[27,29,32]$ and the overlap between sexual and physical childhood abuse and neglect. For example, one study reported that almost half of the neglected children were also victims of physical abuse and about $21 \%$ were also sexually abused [33]. To our knowledge, there have been no prior reviews of experiences of childhood sexual and childhood physical abuse in adult individuals who are homeless. This systematic review aims to provide a comprehensive description of the current knowledge of homeless adults and childhood experiences of physical and sexual abuse. Further, disparities across gender, age, and geographic regions are 
examined. Directions for future research on childhood trauma and homelessness are also identified.

\section{METHOD}

Selection of studies

Using Psychinfo, MEDLINE, the Cochrane Library and a direct library search we sought relevant articles published between January 1990 and August 2013. The search terms that were used include homeless*, child* abuse, child* trauma, and child* adversity. The references cited in the articles that are included in this review were also manually examined to further identify any additional relevant studies. A flow chart summarizing the selection process is presented in Figure 1.

The inclusion criteria required that the studies: i) have a naturalistic research design with data collection predominately from adult individuals who were currently experiencing, or who had previously experienced, homelessness, ii) be published between January 1990 August 2013 in English language, peer-reviewed journals, and iii) include separate reports of the prevalence of childhood sexual abuse (CSA), childhood physical abuse (CPA) or both CSA and CPA in people who were, or previously had been, homeless. Samples were considered to predominately adult if all individuals were aged 16 or over and if the mean age was reported or estimated as 18 or greater. A protocol was used to systematically extract information from each eligible study. ${ }^{1}$

As can be seen in Figure 1, a total of 98 studies were identified from database searches and a manual search. Of these, 48 studies were deemed not relevant (27 studies did not report

\footnotetext{
${ }^{1}$ The protocol is available from: http://www2.ntupsychology.net/ baguley/Sundin_Baguley_protocol_160813.doc
} 
CPA and/or CSA data, and 21 studies reported on children or adolescents). In addition, studies were excluded that only identified a combined abuse score (physical and sexual abuse) and those who only included a select sample of homeless people (mothers or pregnant women; veterans; homeless people who were referred to a mental health intervention). A total of 26 studies were retained. However, detailed examination of the data (including sample characteristics and the dates and location of data collection) indicated that two pairs of studies had samples that may have overlapped. In each case the study that reported a larger data set was included. Consequently, the study by Davis and Winkleby [34] was included in preference to Winkleby and Fleshin [35], and Stein et al. [36] was included in preference to Nyamathi et al. [37].

\section{INSERT FIGURE 1 ABOUT HERE}

All variables of the remaining 24 studies that are relevant for this study are summarized in Table $1[34,36,38-59]$ and, where sufficient information is available, percentage CSA and CPA data are presented for distinct samples (e.g., males and females; whites and non-whites) within each study.

\section{INSERT TABLE 1 ABOUT HERE}

\section{Study characteristics}

For studies where both CPA and CSA data are reported, $n$ is usually identical for each measure, but in a few instances sample sizes differ for CPA and CSA (e.g., presumably because of infrequent events such as non-disclosure or recording error). For this reason $n$ is 
reported separately for CSA and CPA in Table $1 .{ }^{2}$ For each measure the percentage prevalence rate is also reported. Ten studies used randomization $(n=3,768)$, twelve studies had convenience samples $(n=3,118)$ and two employed some form of stratification $(n=$ 2,373). In total 9,730 homeless individuals were included in the sample, a majority of those were recruited from shelters or hostels for the homeless and some were recruited from day centres, soup kitchens, missions or the street.

The studies included in the sample were published between 1990 and 2013; of those, 10 studies were published before 2000 and 15 since 2000 (though the earliest reported date of data collection is 1985). Most of the data are North American in origin; 18 studies collected data in the US $(n=8,230), 2$ in Canada $(n=814)$, and 2 in the UK $(n=215)$. Figure 2 shows the distribution of sample sizes $\left(n_{C S A}\right)$ across the 24 studies. Most are relatively small (with $n$ $<200$ ) and only two studies have total $n$ greater than $1,000[34,48]$. The majority of the studies were of urban samples, although three took national (US) samples and six also included non-urban (rural or suburban) locations. There was also considerable variability between studies in measures used to determine prevalence. Most involved a single interview or questionnaire item, however, five studies use psychometric instruments [42-43,46,52,57]. This included four using the Childhood Trauma Questionnaire (CTQ) [42-43,52,57]. Of these one used the low to moderate cut-off [42] as an indicator for reported abuse, two used the moderate to extreme cut-off $[43,57]$, while the fourth study reported prevalence data for both cut-offs (and was coded for meta-analysis according to the stricter criterion) [52]. Study quality and biases arising from poor quality studies were assessed by inclusion of potential moderators notably those relating to type of sample (e.g., convenience versus random or stratified) and year of study. In addition, to assess the influence variation in the method of

\footnotetext{
${ }^{2}$ Unless otherwise stated subsequent reference in the text is to $n_{C S A}$ (which is generally the larger of the two sample sizes). All statistical models use $n_{C P A}$ or $n_{C S A}$ as appropriate.
} 
obtaining prevalence estimates criteria for reporting abuse were coded either as lenient (including using a low to moderate cut-off for the CTQ) or strict (including a moderate to extreme cut-off for the CTQ) or neither (including where precise wording of the questionnaire or interview question was not reported). A lenient criterion was also coded if only one of multiple items relating to different events were endorsed or if a very broad definition of abuse was used (e.g., "any childhood physical violence" for CPA).

\section{INSERT FIGURE 2 ABOUT HERE}

Five studies provide separate CPA or CSA prevalence (or both) for distinct samples (e.g., male and female or white and non-white). Davis and Winkleby [34] report both CPA and CSA separately for white and non-white samples. Gwadz et al. [43] and North et al. [51] each report both CPA and CSA prevalence rates for males and females. Johnson et al. [45] also provide information on distinct male and female samples, but for CSA only. Koegel et al. [48] report CPA prevalence for the total sample, but provide separate male and female reports of CSA prevalence.

The proportion of homeless males across all samples weighted by sample size was .63 and the weighted proportion of non-white individuals was $.61 .{ }^{3}$ Four studies, D'Ercole and Struening [40], Rayburn et al. [53], Stein et $a l$. [36], and Zlotnick et $a l$. [59] sampled only female participants ( $n=1,708)$, while three, Johnson et $a l$. [45], Kim et al. [47], and Sumerlin [55], had all male samples $(n=599)$. The weighted mean age across all samples was

\footnotetext{
${ }^{3}$ The non-white category included any sample or subsample identified as not of white European origin (e.g., Afro-Caribbean, Asian, and Latino or Hispanic as well as Aborigine and Native American individuals). In most cases this information was taken from published reports (including other studies using the same data), but for a few samples was taken from relevant census data for the location and year of data collection.
} 
estimated as 35.9 years $(S D=9.7$ years $){ }^{4}$ For males the mean age was estimated as 37.1 years $(S D=10.2)$, while for females it was 33.8 years $(S D=8.9)$.

\section{RESULTS}

All meta-analyses were conducted via restricted maximum likelihood estimation (REML) estimation using the metafor package [60] in $\mathrm{R}$ [61] with restricted maximum likelihood estimation (REML) used to obtain parameter estimates. A number of effect size metrics can be adopted for proportions (including prevalence rates). Meta-analysis of the raw proportions is problematic if prevalence rates range widely - particularly if any are close to $0 \%$ or $100 \%$ (as is the case here). Standard meta-analytic methods assume a normal or near-normal distribution of sampling error and constant error variance. The constant variance assumption is likely to be severely violated for prevalence rates where the variance is a function of the rate (being higher for proportions close to the upper or lower limit). For this reason the preferred approach is to transform the proportion prior to analysis (e.g., using the logistic transformation or Freeman-Tukey transformation). Here the logistic transformation performs marginally better (resulting in less heterogeneity) as well as having a more intuitive interpretation (in terms of the log odds of sexual or physical abuse). For all analyses a random effects model is preferred (it being implausible that the true proportion is fixed between study locations or over time). Standard meta-analytic approaches assume that the variances of the original samples are known and produce standard errors that are too small. For this reason a correction to the standard errors that involves a change in test statistic from $z$ to $t$ was employed $[60,62]$. Models with moderator effects were compared using Akaike information criterion (AIC) using maximum likelihood estimation. This measure assesses the

\footnotetext{
${ }^{4}$ Age data are taken from published reports or estimated from available information (e.g., the median or the proportion of the sample falling into different age categories).
} 
informativeness of a model [e.g., see 63], and advantages simpler models (i.e., those with fewer parameters).

\section{Meta-analysis of CPA}

The initial analysis included no moderator variables and included all 26 samples that reported the proportion of CPA. In this analysis the weighted mean estimate of the log odds of CPA was $-0.520,95 \% \mathrm{CI}[-1.099,0.058]$, corresponding to a proportion of $37 \%, 95 \% \mathrm{CI}[25,51]$, $\mathrm{AIC}=95.5$. Figure $3 \mathrm{a}$ shows a forest plot of the proportions (on an untransformed scale), while Figure $3 \mathrm{~b}$ shows the corresponding funnel plot.

\section{INSERT FIGURE 3 ABOUT HERE}

Both plots suggest substantial variability in the proportion of CPA between samples. Indeed, the level of heterogeneity in the estimates is very large and $I^{2}=.99, Q(25)=1601.4, p<$ .0001 , indicating that almost all the variability in the estimates is attributable to variation between samples rather than sampling error.

Given the diverse composition of the samples and the likelihood that CPA is related to one or more of these factors, heterogeneity of the estimate is to be expected. It is therefore instructive to account for some or all of the heterogeneity by modelling the prevalence of CPA as a function of potential moderator variables - notably demographics. A preliminary analysis included the year of the study, the proportion of white participants, the proportion of male participants and average age as predictors. Age and year of study were centred prior to entry in the model. The resulting model is much more informative than the model with no moderators $\left(\mathrm{AIC}=76.8, \Delta_{\mathrm{AIC}}=-18.6\right)$. A reduction in $\mathrm{AIC}$ of this magnitude is considered very strong evidence in favour of the more informative model. The estimate of residual 
heterogeneity was also reduced, from $\tau^{2}=1.95$ to $\tau^{2}=0.74$. Thus these four moderators account for over sixty percent of between-study heterogeneity $\left(R_{\text {meta }}^{R}=.62\right)$, although considerable heterogeneity remains [see 64]. Three further dichotomous moderators reflecting other available study characteristics were added. These characteristics were whether the sample was US only, whether it included non-urban areas and whether or not a convenience sample was used (rather than stratified or random). Adding these moderators did not reduce heterogeneity and resulted in a less informative model $\left(\mathrm{AIC}=81.5, \Delta_{\mathrm{AIC}}=4.7\right)$.

For the final set of analyses the presence of interaction effects between the year of study, proportion of white, proportion of male and average age moderator effects was considered. Adding two-way interactions between all four effects did not improve the model relative to the main effects only model $\left(\mathrm{AIC}=78.5, \Delta_{\mathrm{AIC}}=1.7\right)$.

A final check was to add predictors coding lenient or strict criteria for CPA. Adding the strict criterion, but not the lenient criterion $\left(\mathrm{AIC}=78.0, \Delta_{\mathrm{AIC}}=1.1\right)$, improved model fit $\left(\mathrm{AIC}=72.6, \Delta_{\mathrm{AIC}}=4.3\right)$ and further reduced heterogeneity $\left(R_{\text {meta }}^{2}=.68\right)$. The final model that we report is therefore the initial model including year of study, key demographic variables and the strict criterion for determining CPA. Parameter estimates and confidence intervals for this model on the transformed (log odds) scale are presented in Table 2.

\section{INSERT TABLE 2 ABOUT HERE}

Table 2 indicates that more recent studies show higher prevalence rates (perhaps indicating changes in willingness to report CPA over time or changes in how CPA is perceived or defined by researchers). Age is also associated with prevalence - with younger samples tending to report higher rates of CPA. Although age may be confounded with length of 
homelessness or frequency of homeless episodes, it seems plausible that CPA is a trigger for homelessness in young adults but plays a more indirect role among older adults. Prevalence of CPA also tends to be higher in predominately white homeless samples, but there is little indication of a difference between males and females. This pattern is illustrated in Figure 4, which illustrates the predicted prevalence of CPA for a 2010 study as a function of the proportion of white participants for all male or all female samples when average age is 18,35 or 55. Figure 4 plots estimates when the strict criterion for determining CPA is not used. Employing a strict criterion for CPA (using a moderate to severe cut-off on the CTQ) decreased prevalence estimates. For purposes of comparison it is interesting to revise our estimate of prevalence from the overall model assuming that the strict criterion was used in each study (but not adjusting for other covariates). This reduces the prevalence estimate from $37 \%$ to $29 \%, 95 \% \mathrm{CI}[8,65]$.

\section{INSERT FIGURE 4 ABOUT HERE}

\section{Meta-analysis of CSA}

For the 29 samples that report CSA, a meta-analysis with no moderators gives the weighted mean estimate of the log odds of CPA as $-1.106,95 \%$ CI [-1.523, -0.688$]$. AIC for the model is 94.7 and the estimate corresponds to CSA prevalence of .25, 95\% CI [.18, .33]. There is also considerable heterogeneity in the prevalence of CSA between samples, $I^{2}=.98, Q(28)=$ $1227.5, p<.0001$. Around $98 \%$ of the variation is attributable to between-study differences. Figure 5 shows a forest and funnel plot for the initial model. 
As for CPA, year of study, average age (both centered) and the proportion of white or male participants were added to the model as moderators. This model was more informative than the model with no moderators $\left(\mathrm{AIC}=66.3, \Delta_{\mathrm{AIC}}=-24.5\right)$ and also reduced the residual heterogeneity of the model from $\tau^{2}=1.168$ to $\tau^{2}=0.429$. Adding these moderators thus accounts for over $60 \%$ of between-study variability ( $R_{\text {meta }}^{2}=.63$ ). Adding additional study characteristics (whether the sample was US only, whether it included non-urban areas and whether convenience sampling was employed) produced a slightly more informative model $\left(\mathrm{AIC}=63.9, \Delta_{\mathrm{AIC}}=-2.3\right)$ and accounting for nearly $70 \%$ of between-study variability $\left(R_{\text {meta }}^{2}\right.$ $=.69$ ). According to this model CSA prevalence may be slightly lower for US samples and slightly higher in convenience samples (relative to stratified or random samples), but there was no indication that samples including non-urban areas differed from urban samples.

An interaction model containing two-way interactions between key demographic factors (average age and the proportions of white and male homeless) was also tested, there being insufficient degrees of freedom to estimate interactions between all predictors. This model was less informative than the preceding model $\left(\mathrm{AIC}=69.6, \Delta_{\mathrm{AIC}}=5.7\right)$.

The final step in the analysis was to add predictors for lenient and strict CSA criteria. Neither lenient $\left(\mathrm{AIC}=65.2, \Delta_{\mathrm{AIC}}=1.2\right)$, nor strict $\left(\mathrm{AIC}=65.9, \Delta_{\mathrm{AIC}}=2.0\right)$ criteria improved model fit. The absence of effect of an effect of the strict criterion may reflect the sensitivity of CSA measurement items to other factors (e.g., rapport with the interviewer or differences in interpretation of terms such as 'abuse'). Accordingly, the final preferred model includes the same predictors as for CPA with the addition of indicators for convenience sampling, samples of US origin and samples that included non-urban areas, but excluding criterion 
strictness. Parameter estimates and confidence intervals for this model on the transformed scale are presented in Table 3.

\section{INSERT TABLE 3 ABOUT HERE}

The results summarized in Table 3 indicate that recent studies are associated with reports of higher CSA prevalence, matching the pattern found for CPA. The effects of the proportion of white and male participants is, however, different than for CPA. Prevalence is strongly associated with the proportion of females in the sample, but unlike the tendency observed for physical abuse, there was no association with the proportion of white homeless in the sample and also little indication that CSA changed with age. US samples tend to have slightly lower prevalence rates than non-US samples and convenience samples have slightly higher estimates of prevalence (the latter possibly indicating a slight sampling bias).

The most striking finding is that prevalence of CSA is far higher for female homeless, $32.3 \% 95 \%$ CI $[22.7,43.7]$ than male homeless participants, $10.3 \% 95 \%[6.1,17.1] .{ }^{5}$ Figure 6 shows the predicted prevalence of CSA for a 2010 study as a function of the proportion of white homeless by sex and average age. Comparison with Figure 4 reveals the large difference in predicted prevalence between males and females for CSA (in comparison to the modest difference for CPA).

\section{INSERT FIGURE 6 ABOUT HERE}

\footnotetext{
${ }^{5}$ These estimates were obtained from the final model with all other covariates except the indicator for convenience sampling centered. Thus the estimates reflect the average estimate for a random or stratified sample rather than for a convenience sample.
} 


\section{Publication bias}

Funnel plots for meta-analysis of CSA and CPA are dominated by between-sample heterogeneity, which can both cause asymmetry in the plots or make asymmetry owing to publication bias harder to detect [e.g., see 65]. Asymmetry, like any other systematic pattern in the data, may also be caused by unaccounted for covariates [66]. For this reason asymmetry was assessed for each of the final models using the D-var version of Egger's regression test [67]. For neither the CPA final model, $t(19)=0.95, p=.35$, nor the CSA final model, $t(20)=0.25, p=.81$, does the regression test detect asymmetry. It is also important to consider the mechanism for publication bias, which is likely to be a filtering out of statistically non-significant effects via non-submission or biases operating at the publication stage. This mechanism is perhaps implausible for CSA and CPA measures as they were typically not the primary measures reported in the studies surveyed here and there would be no obvious statistical threshold upon which a filter could act.

\section{DISCUSSION}

This systematic review reveals several striking patterns in the prevalence of childhood physical and sexual abuse in adult homeless samples. Most notably, prevalence rates tend to be far higher for the homeless samples than for the general population. Thus, this study estimated the average prevalence of childhood physical abuse at $37 \%$, which should be compared to the estimated rates of physical child abuse to be between 4 and $16 \%$ in the general populations in the USA, Australia and the UK [26]. Obtaining prevalence assuming that a stricter criterion was used (a moderate to extreme cut-off for the CTQ) reduces this 
estimate to $29 \% .{ }^{6}$ Our review estimated the average prevalence of childhood sexual abuse at $32 \%$ for females and $10 \%$ for males compared to $7.5 \%$ of all children in the general population ( $10 \%$ for females, $5 \%$ for males) [26]. Although there is a huge variation in the estimates presented in this study, much of the variability is explained through demographic factors such as age, gender or ethnicity. For physical, but not sexual abuse, samples with lower average age tended to have higher prevalence rates. These findings are in line with previous research that showed childhood physical abuse to be risk factors for homelessness, with younger homeless people perhaps more likely to have left parental or non-parental care to escape abuse [e.g., 46,47,52]. It may also partly explain why one large study with a predominately older sample suggested that homeless adults were not disproportionately physically abused as children [48]. Also, a small body of research suggests that young people affected by abuse and neglect risk poor academic achievement at school, which may lead to difficulties finding employment in adulthood [26], and, in turn, unemployment is a strong cause of homelessness [1-3]. In contrast, older samples likely contain higher proportions of homeless caused by other factors (e.g., living conditions associated with poverty) $[3,49]$. Furthermore, some variability in measurement and some of the heterogeneity between studies is likely to be due to differences in measurement procedures - whether the precise wording of items, interpretation of items by participants or rapport with the interviewer.

Prevalence rates are also higher for more recent studies. While it is tempting to conclude that this finding reflects an increase in study quality - with more recent studies providing more accurate estimates, it may also be explained by other factors (e.g., an increase

\footnotetext{
${ }^{6}$ Note however that the definitions of CPA and CSA used in general populations research are less strict than implied by the strict criterion implied by a moderate to severe cut-off with the CTQ [see 26, Table 1].
} 
over time of child abuse in homeless people or reduced stigma leading to greater willingness to disclose; the most recent studies also tended to have small sample sizes).

The moderator analysis suggests a slightly higher prevalence of childhood physical abuse for predominately white samples. Also consistent with previous research, the prevalence of childhood sexual abuse is markedly higher for predominately female samples than for male samples $[36,58]$. But while previous research indicated that homeless women who report having been abused as children also report higher rates of violence as adults (see e.g., 59-62], this issue was not investigated in the present study. There is also little or no evidence in our study of an association between race and prevalence of childhood sexual abuse.

Although the moderator analyses present interpretable patterns that are broadly consistent with previous literature, there are potential threats to the validity and generality of the analysis. First, the heterogeneity of the prevalence rates - while not unexpected (given the complex, multifactorial nature of homelessness and childhood abuse) - implies that there remains considerable unexplained between-study variability in prevalence (around 30\% for both analyses). Second, the samples are predominately urban and from Western, Englishspeaking countries and this greatly limits generalizability (given that these are probably atypical homeless populations in a global context). Indeed even within our analyses there was some evidence - albeit weak - that US prevalence rates of sexual abuse among homeless people were slightly lower than for the non-US samples. Taken together with the higher prevalence rates for recent studies, we propose that future research should focus on crossnational, multi-sample studies with common recruitment criteria and common measurement instruments. This may help to eliminate noise in the prevalence estimates between studies and enable other sources of heterogeneity to be measured and modelled. 
Several issues with the retrospective data collection used in the studies included in our analysis need to be considered; the studies may suffer from recall bias because it is impossible to establish whether consequences are due to the actual abuse experience, events that occurred after the abuse experience, or a person's cognitive appraisal of the experience. Other weaknesses of studies using retrospective measurement of childhood abuse include selective inclusion of participants and limited or no opportunity to adjust for social and individual confounding factors as they occur. Our own analyses suggest that convenience samples lead to slightly higher estimates of sexual abuse (but not physical abuse) - potential evidence that sampling strategy does bias estimates. However, it should be pointed out that the majority of homeless research uses retrospective data collection, and recall bias is common to all such studies and that there is no reason to assume that the magnitude or direction of bias is different here. There is further comfort in the broad consistency of estimates between studies that use validated instruments such as the CTQ $[42-43,52,57]$ with those that do not (though - as noted - adopting a strict cut-off on the CTQ does produce lower estimates of CPA).

\section{Conclusions}

The substantial heterogeneity between the studies included in the review was not unexpected. One of the findings of this review is that younger people were more likely than older people to report having experienced both physical and sexual abuse during childhood. However, this finding warrants caution as it may be the case that older people report less exposure to trauma than younger people. Longitudinal studies of cohorts of younger and older people who have experienced abuse would help clarify the risk for and routes into homelessness, and identify factors that can prevent homelessness in such populations. Likewise, women were more likely to report childhood sexual abuse compared to men, and 
longitudinal research can highlight factors that can contribute to homelessness among women who have been sexually abused as a child. Some of the variation between studies could not be explained by demographics such as sex, age, or race, and this emphasises the need to standardize recruitment and measurement procedures (notably measurement instrument) in order to allow for comparisons across studies as well as study sites.

This is the first systematic review of childhood physical and sexual abuse in adult people who are homeless showing that younger individuals and individuals who are white are more likely to report having experienced child physical abuse compared to those who are older and non-white and that female homeless are more likely to have experienced sexual abuse than male homeless regardless of age or ethnicity. As such, the review has important implications for health services for the homeless. Victims of childhood abuse who are homeless, or become homeless later in life, have experienced multiple, severe forms of trauma and the impact on their psychological as well as physical health is often multiple and severe. This condition is sometimes referred to as complex posttraumatic disturbance or 'complex trauma' [68-69]. Complex trauma has been defined as "a combination of early and late-onset, multiple, and sometimes highly invasive traumatic events, usually of an ongoing, interpersonal nature" [70, p 1]. Several authors [70-71-73] have recommended trauma informed care models for people who have experienced complex trauma, including childhood abuse, and are homeless. These interventions are often based on Herman's [68] phased treatment model, where a) the initial phase is the establishment of a therapeutic relationship; followed by b) improving the safety of trauma sufferers with regard to health, emotions, relationships, substances and environment; c) helping sufferers to make sense of the traumatic experience, to understand how the traumatic experience impacts on them in their current life, and to develop more adaptive ways of coping. From this skills based 
understanding, individuals are then encouraged to make connections within the community for support in the longer term.

In conclusion, this study indicates that childhood physical and sexual abuse is more prevalent among the homeless in Western countries than in the global population. Agencies who work with people experiencing homelessness should take more account of childhood trauma among service users. 


\begin{abstract}
Acknowledgements
The authors wish to thank the anonymous reviewers for their valuable comments and suggestions to improve the quality of the paper. The authors also wish to thank Helen Baldwin for her assistance in reviewing the literature.
\end{abstract}

\title{
Conflict of interest
}

On behalf of all authors, the corresponding author states that there is no conflict of interest. 


\section{REFERENCES}

1. Carlen P (1996) Jigsaw: A political criminology of youth homelessness. Buckingham: Open University Press

2. Elliott M, Krivo L (1991) Structural determinants of homelessness in U.S. Cities. Social Problems 38:113-131

3. Philippot P, Lecocq C, Sempoux F, Nachtergael H, Galand B (2007) Psychological research on homelessness in Western Europe: a review from 1970 to 2001. J Soc Issues 13:483-503

4. Dachner N, Tarasuk V (2002) Homeless "squeegee kids": Food insecurity and daily survival. Soc Sci Med 54: 1039-1049

5. Fitzpatrick S, Stephens M (2007) An international review of homelessness and social housing policy. London: Communities and Local Government.

6. Kushel MB, Vittinghoff E, Haas JS (2001) Factors associated with the health care utilization of homeless persons. JAMA 285: 200-206

7. Vostanis P, Tischler V, Cumella, S, Bellerby T (2001) Mental health problems and social supports among homeless mothers and children victims of domestic and community violence. Int J Soc Psychiatry 47: 30-40

8. Maguire N, Johnson R, Vostanis P, Keats H, Remington RE (2010) Mental health good practice guide: meeting the psychological and emotional needs of homeless people, National Mental Health Development Unit and the Department for Communities and Local Government

9. Baggett TP, Hwang SW, O'Connell JJ, Porneala BC, Stringfellow EJ, et al. (2013) Mortality among homeless adults in Boston: shifts in causes of death over a 15-year period. JAMA Intern Med 173: 189-195 
10. Fitzpatrick S, Stephens M (2008) The future of social housing. London: Shelter. 167p

11. Kenway P, Palmer G (2003) How many, how much? London: New Policy Institute p24

12. U.S. Conference of Mayors (2008) Status report on hunger \& homelessness. Available from http://usmayors.org/pressreleases/uploads/2012/1219-report-HH.pdf

13. Koegel P, Burnham MA, Farr RK (1988) The prevalence of specific psychiatric disorders among homeless individuals in the inner city of Los Angeles. Arch Gen Psychiatry 45: 1085-1092

14. North CS, Eyrich KM, Pollio DE, Spitznagel EL (2004) Are rates of psychiatric disorders in the homeless population changing? Am J Public Health 94: 103-108

15. Nielsen SF, Hjorthøj CR, Erlangsen A, Nordentoft M (2011). Psychiatric disorders and mortality among people in homeless shelters in Denmark: a nationwide registerbased cohort study. Lancet 377: 2205-2214

16. Dennis DL, Buckner JC, Lipton, FR, Levine IS (1991) A decade of research and services for homeless mentally ill persons: Where do we stand? American Psychol 46: $1129-1138$

17. Fazel S, Khosla V, Doll H, Geddes J (2008) The prevalence of mental disorders among the homeless in Western countries: systematic review and meta-regression analysis. PLOS Medicine 5: 1670-1681

18. Fischer PJ, Breakey WR (1991) The epidemiology of alcohol, drug, and mental disorders among homeless persons. Am Psychol 46: 1115-1528

19. Folsom D, Jeste DV (2002) Schizophrenia in homeless persons: a systematic review of the literature Acta Psychiatr Scand 105:404-413

20. Scott J (1993) Homelessness and mental illness. Brit J Psychiatry 162: 314-324 
21. Seligman MEP, Maier SF (1967) Failure to escape traumatic shock. J Exp Psychol, 74: $1-9$

22. Flannery, RB Jr. (1987). From victim to survivor: A stress management approach in the treatment of learned helplessness (pp. 217-233). In B.A. van der Kolk (Ed.), Psychological trauma. Washington, DC: American Psychiatric Press.

23. Goodman LA, Saxe L, Harvey M (1991) Homelessness as psychological trauma: Broadening perspectives. Am Psychol, 46:1219-1225

24. Scaglia O (2008) Homelessness and helplessness: Correlating learned helplessness, locus of control, and perceived social support with chronic homelessness. Minneapolis, MN: Capella University

25. Dallam SJ (2001) The long-term medical consequences of childhood trauma. In K Franey, R Geffner, R Falconer (Eds), The cost of child maltreatment: Who pays? We all do (pp. 1-14), San Diego, CA: FVSAI Publications

26. Gilbert R, Spatz Widom C, Browne K., Fergusson D, Webb E, et al. (2009) Burden and consequences of child maltreatment in high-income countries. Lancet 373: 68-81.

27. Dubowitz H (2007) Understanding and addressing the "neglect of neglect:" Digging into the molehill. Child Abuse Negl 31:603-606

28. Mayer M, Lavergne C, Tourigny M, Wright J (2007) Characteristics differentiating neglected children from other reported children. J Fam Violence 31:607-614

29. McSherry D (2007) Commentary: Understanding and addressing the "neglect of neglect": Why are we making a mole-hill out of a mountain? Child Abuse Negl 31:607-614

30. McSherry, D. (2011). Lest we forget: Remembering the consequences of child neglect - a clarion call to 'feisty advocates'. Child Care in Practice 17:103-113 
31. Wolock I, Horowitz B (1984) Child maltreatment as a social problem: The neglect of neglect. Am J Orthopsych 54:530-543

32. Garbarino J, Collins CC (1999) Child neglect: The family with a hole in the middle. In H Dubowitz (Ed.), Neglected children: Research, practice, and policy (pp. 1-23) Thousandf Oaks, CA: Sage.

33. Mennen FE, Trickett P (2010) Mental health services to urban minority children. Child Youth Serv Rev 29:1220-1234

34. *Davis LA, Winkleby MA (1993) Sociodemographic and health-related risk factors among African-American, Caucasian and Hispanic homeless men: A comparative study. Journal of Social Distress and the Homeless 2: 83-101

35. Winkleby MA, Fleshin D (1993) Physical, addictive, and psychiatric disorders among homeless veterans and nonveterans. Public Health Rep 108: 30-36

36. *Stein JA, Leslie MB, Nyamathi A (2002) Relative contributions of parent substance use and childhood maltreatment to chronic homelessness. Child Abuse Negl $261011-$ 1027

37. Nyamathi A, Wenzel SL, Lesser J, Flaskerud, Leake B (2001) Comparison of psychosocial and behavioral profiles of victimized and nonvictimized homeless women and their intimate partners Res Nurs Health 24: 324-335

38. *Breton M, Bunston T (1992) Physical and sexual violence in the lives of homeless women. Can J Commun Ment Health 11: 29-44.

39. *Craig TKJ, Hodson S (1998) Homeless youth in London: I. Childhood antecedents and psychiatric disorder. Psychol Med 28: 1379-1388.

40. *D'Ercole A, Struening E (1990) Victimization among homeless women: Implications for service delivery. J Community Psychol 18: 141-152 
41. *Dietz TL (2009) Drug and alcohol use among homeless older adults. Predictors of reported current and lifetime substance misuse problems in a national sample. J Appl Gerontol 28: 235-255

42. *Forde DR, Baron SW, Scheck, Stein MB (2012) Factor structure and reliability of the Childhood Trauma Questionnaire and prevalence estimates of trauma for male and female street-youth. J Interpers Violence 27. 364-379

43. *Gwadz MV, Nish D, Leonard NR, Strauss SM. (2007) Gender differences in traumatic events and rates of post-traumatic stress disorder among homeless youth. J Adolesc 30:117-129

44. *Herman DB, Susser ES, Struening EL, Link BL (1997) Adverse childhood experiences: are they risk factors for adult homelessness? Am J Public Health 87: 249-255

45. *Johnson R, Rew L, Sternglanz RW (2006) The relationship between childhood sexual abuse and sexual health practices of homeless adolescents. Adolescence 41: $221-234$

46. *Keeshin BR, Campbell K (2011) Screening homeless youth for histories of abuse: Prevalence, enduring effects, and interest in treatment. Child Abuse Negl 35: 401-407

47. *Kim MM, Ford JD, Howard DL, Bradford DW (2010) Assessing trauma, substance abuse, and mental health in a sample of homeless men. Health Soc Work 35: 39-48

48. *Koegel P, Melamid E, Burnam A (1995) Childhood risk factors for homelessness among homeless adults. Am J Public Health 85: 1642-1649

49. *Melander LA, Tyler KA (2010) The effect of early maltreatment, victimization, and partner violence on HIV risk behavior among homeless young adults. J Adolesc Health 47, 2010: 575-581 
50. *Morrell-Bellai T, Goering PN, Boydell KM (2000) Becoming and remaining homeless: a qualitative investigation. Issues Ment Health Nurs 21: 581-604.

51. *North CS, Smith EM, Spitznagel EL 1994 Violence and the homeless: An epidemiologic study of victimization and aggression. J Trauma Stress 7: 95-110

52. *Pluck G, Lee KW, David R, Macleod DC, Spence et al., (2011) Neurobehavioural and cognitive function is linked to childhood trauma in homeless adults. Brit J Clin Psychol 50: 33-45

53. *Rayburn NR, Wenzel SL, Elliott MN, Hambarsoomians K, Marshall, JN, et al. (2005). Trauma, depression, coping, and mental health service seeking among impoverished women. J Consult Clin Psychol 73: 667-677

54. *Shelton KH, Taylor P, Bonner A, van den Bree (2009). Risk factors for homelessness: Evidence from a population-based study. Psychiatric Services 60: 465472

55. *Sumerlin JR (1999) Cognitive-affective preparation for homelessness: quantitative and qualitative analyses of childhood out-of-home placement and child abuse in a sample of homeless men. Psychol Rep 85:553-573

56. *Tam TW, Zlotnick C, Robertson MJ (2003) Longitudinal perspective: adverse childhood events, substance use, and labor force participation among homeless adults. Am J Drug Alcohol Abuse 29:829-846

57. *Torchalla, I., Strehlau, V., Li, K., Schuetz, C., \& Krausz, M. (2012). The association between childhood maltreatment subtypes and current suicide risk among homeless men and women. Child Maltreat, 17,132-143.

58. *Tyler KA (2006) A qualitative study of early family histories and transitions of homeless youth. J Interpers Violence 21: 1385-1393 
59. *Zlotnick C, Robertson MJ, Wright MA (1999) The impact of childhood foster care and other out-of-home placement on homeless women and their children. Child Abuse Negl 23:1057-1068

60. Viechtbauer W (2010) metafor: Meta-Analysis Package for R. R package version 1.01. http://CRAN.R-project.org/package=metafor

61. R Development Core Team (2012). R: A language and environment for statistical computing. Vienna, Austria: R Foundation for Statistical Computing.

62. Knapp G, Hartung J (2003) Improved tests for a random effects meta-regression with a single covariate. Stat Med 22: 2693-2710

63. Baguley T (2012) Serious stats: A guide to advanced statistics for the behavioral sciences. Basingstoke: Palgrave. 864p

64. Aloe AM, Becker J, Pigott TD (2010) An alternative to R2 for assessing linear models of effect size. Res Syn Meth 1: 272-283

65. Peters JL, Sutton AJ, Jones DR, Abrams KR, Rushton L, et al. (2010) Assessing publication bias in meta-analyses in the presence of between-study heterogeneity. J R Stat Soc Ser A Stat Soc 173: 575-591

66. Sutton AJ, Higgins JPT (2008) Recent developments in meta-analysis. Stat Med 27: $625-650$

67. Moreno S, Sutton A, Ades AE, Stanley T, Abrams K, et al. (2009) Assessment of regression-based methods to adjust for publication bias through a comprehensive simulation study. BMC Med Res Methodol 9: 2 doi:10.1186/1471-2288-9-2

68. Herman JL (1992) Complex PTSD: A syndrome in survivors of prolonged and repeated trauma. J Trauma Stress 5: 377-391 
69. Roth S, Newman E, Pelcovitz D, Van Der Kolk B, Mandel F S (1997) Complex PTSD in victims exposed to sexual and physical abuse: Results from the DSM-IV Field Trial for Posttraumatic Stress Disorder. J Trauma Stress, 10: 539-555

70. Briere J, Lanktree CB (2013) Integrative treatment of complex trauma for adolescents (ITCT-A): A guide for the treatment of multiply-traumatized youth, $2^{\text {nd }}$ edition. Los Angeles, CA: USC Adolescent Trauma Treatment Training Center, National Child Traumatic Stress Network, U.S. Department of Substance Abuse and Mental Health Services Administration.

71. Guarino K (2012) Developing a trauma-informed approach to serving young homeless families. Needham, MA: The National Center on Family Homelessness.

72. Hopper EK, Bassuk EL, Olivet J (2010) Shelter from the storm: Trauma-informed care in homeless service settings. The Open Health Services and Policy Journal 3:80100

73. Hutchinson S, Page A, Sample E (2014) Rebuilding Shattered Lives: The final report - Getting the right help at the right time to women who are homeless or at risk, London: St. Mungo's. 
Figure

Figure 1. Prisma Flow Diagram summarizing selection of studies for the meta-analysis

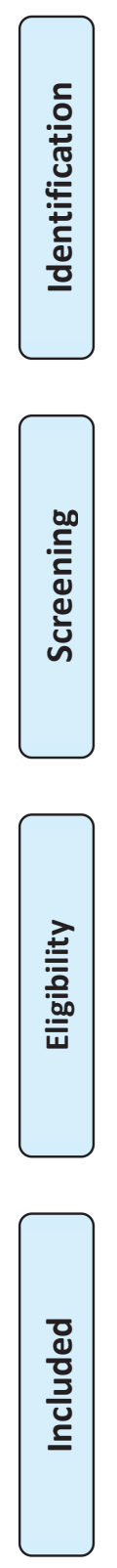

Records identified through database searching $(n=93)$
Additional records identified through other sources

$(n=5)$

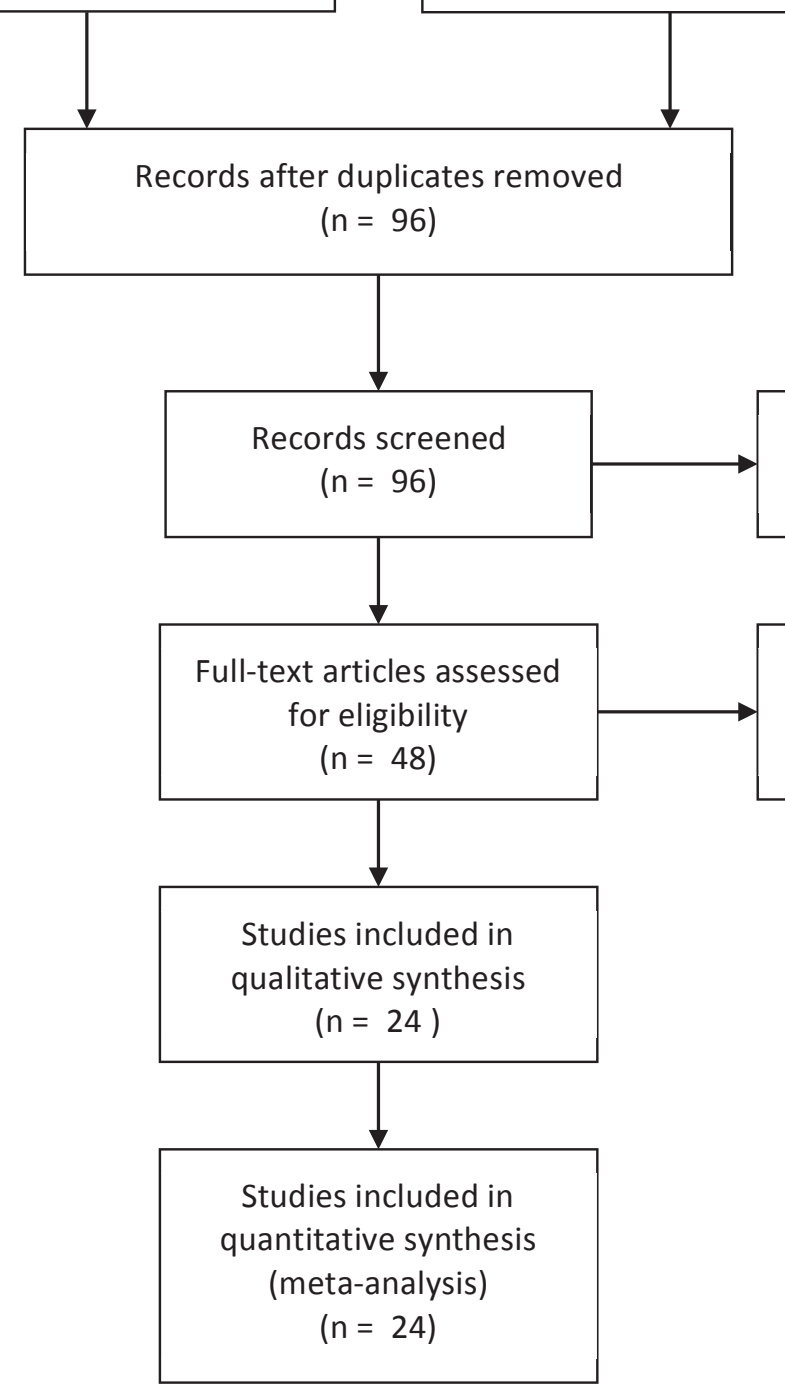

Records excluded $(n=48)$

Full-text articles excluded, with reasons

$(n=24)$

From: Moher D, Liberati A, Tetzlaff J, Altman DG, The PRISMA Group (2009). Preferred Reporting /tems for Systematic Reviews and MetaAnalyses: The PRISMA Statement. PLoS Med 6(6): e1000097. doi:10.1371/journal.pmed1000097 
Figure 2: Distribution of study sample sizes

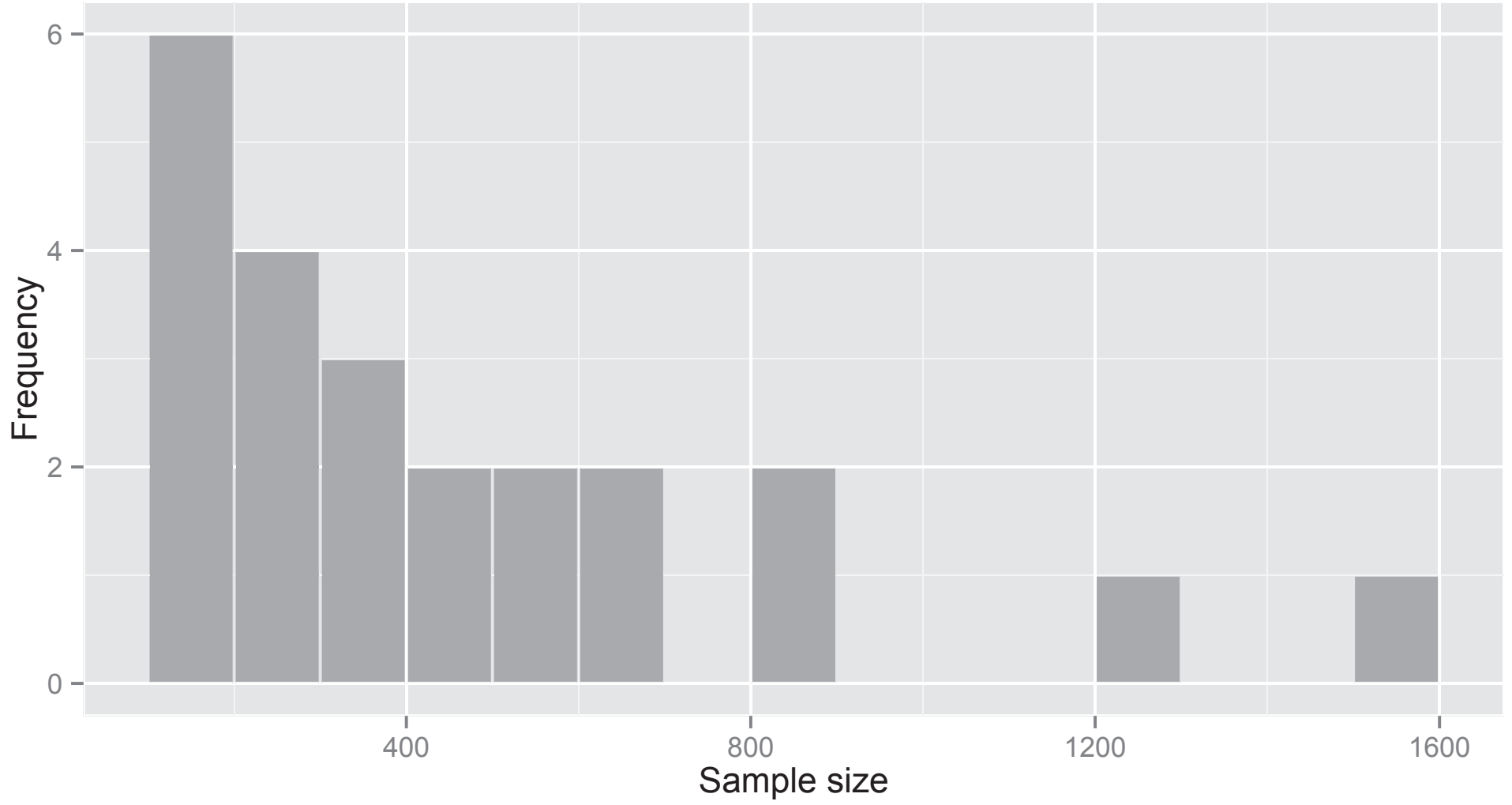


Figure

Figure 3. Forest and funnel plots for the meta-analysis of child physical abuse.

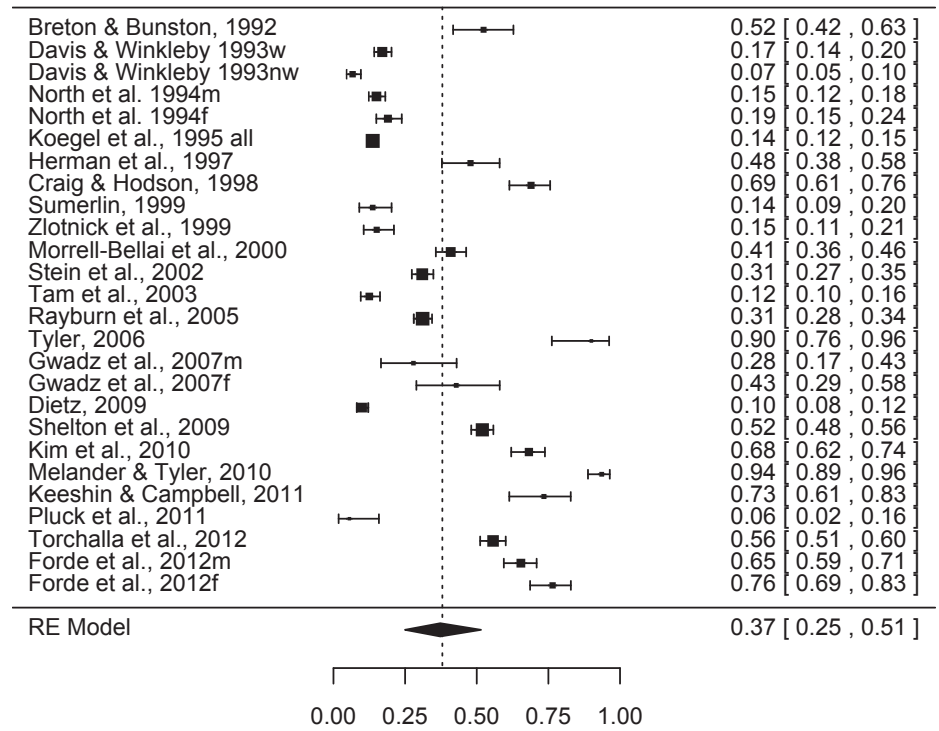

Proportion of sample reporting childhood physical abuse

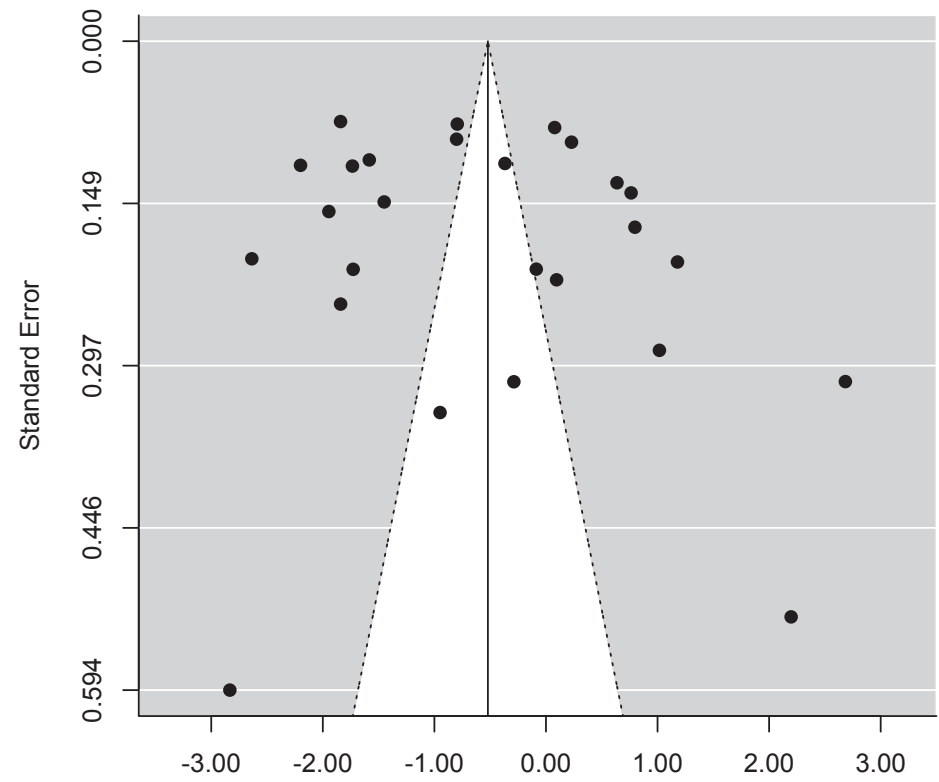

Log odds of childhood physical abuse 
Figure

Figure 4. Prevalence of physical abuse as a function of demographic factors.

(a) Average age $=18$ years

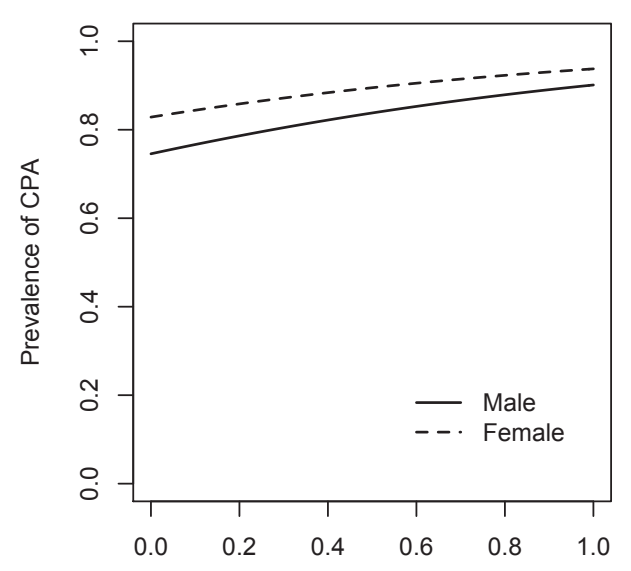

Proportion of White homeless in sample (b) Average age $=35$ years

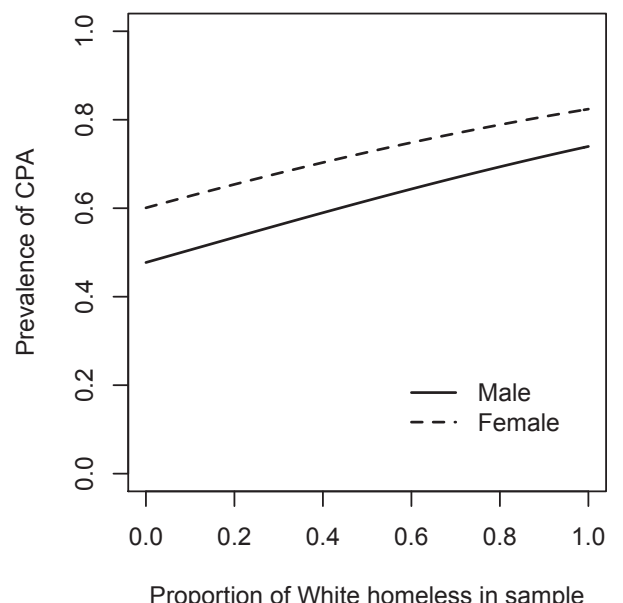

Proportion of White homeless in sample (c) Average age $=55$ years

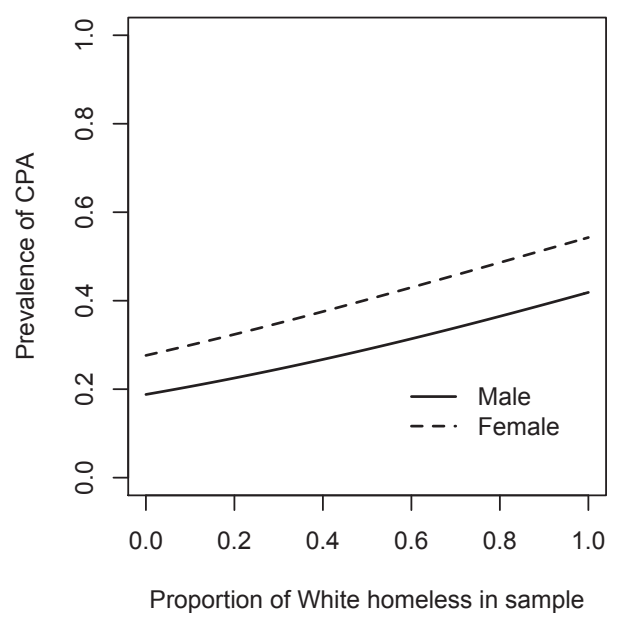


Figure

Figure 5. Forest and funnel plots for the meta-analysis of child sexual abuse.

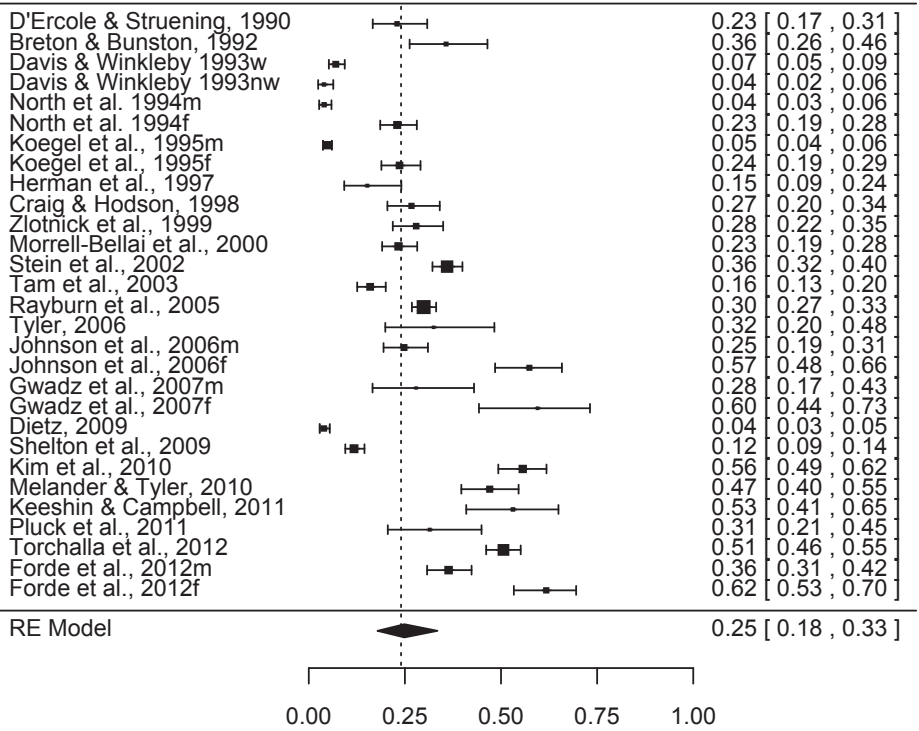

Proportion of sample reporting childhood sexual abuse

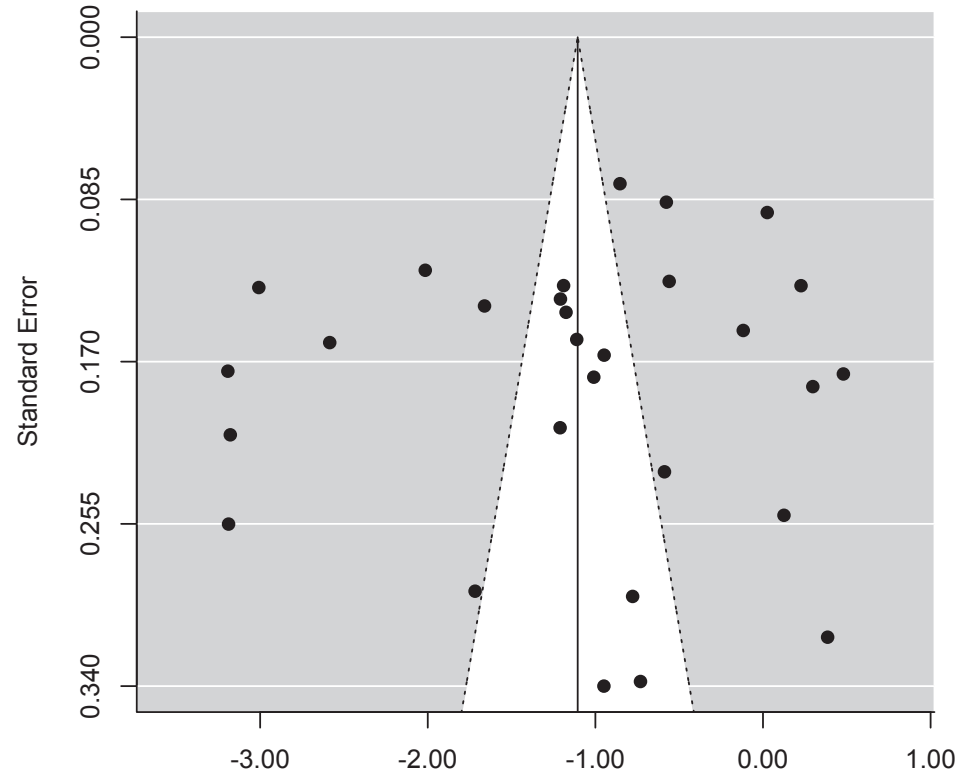

Log odds of childhood sexual abuse 
Figure

Figure 6. Prevalence of sexual abuse as a function of demographic factors.

(a) Average age $=18$ years

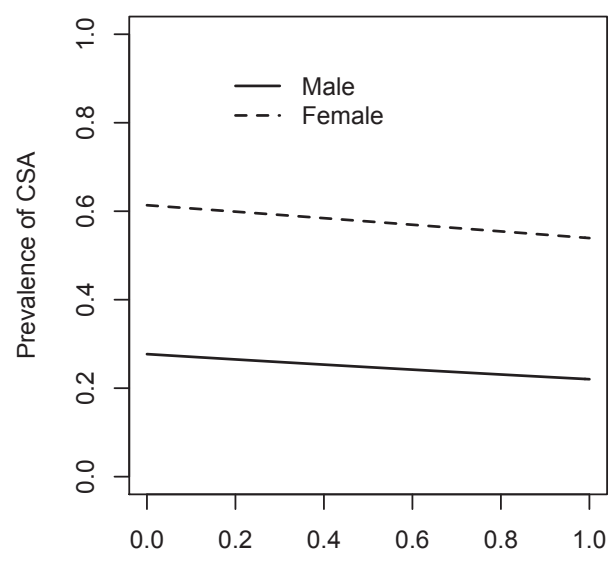

Proportion of White homeless in sample (b) Average age $=35$ years

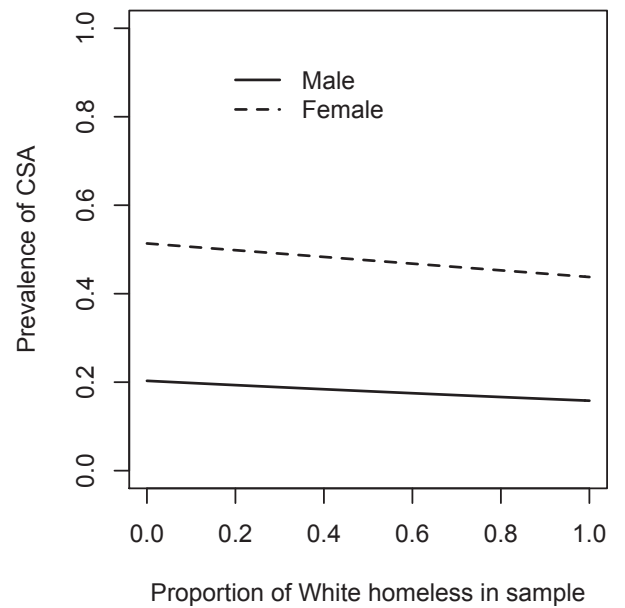

(c) Average age $=55$ years

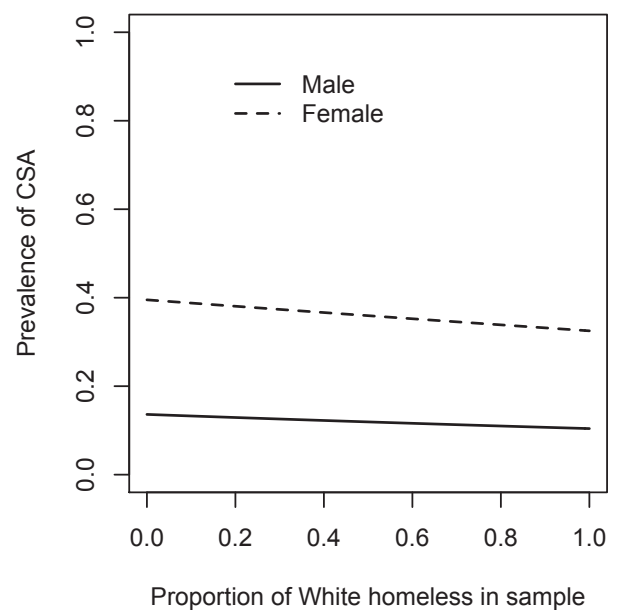

